\title{
Use of Cold Atmospheric Plasma to Detoxify Hazelnuts from Aflatoxins
}

\author{
Ilenia Siciliano ${ }^{1, \dagger}$, Davide Spadaro ${ }^{1,2, *,+}$, Ambra Prelle ${ }^{2}$, Dario Vallauri ${ }^{3}$, \\ Maria Chiara Cavallero ${ }^{3}$, Angelo Garibaldi ${ }^{1}$ and Maria Lodovica Gullino ${ }^{1,2}$ \\ 1 Agroinnova-Centre of Competence for the Innovation in the Agro-Environmental Sector, \\ University of Turin, Largo Paolo Braccini, 2 Grugliasco, Turin 10095, Italy; ilenia.siciliano@unito.it (I.S.); \\ angelo.garibaldi@unito.it (A.G.); marialodovica.gullino@unito.it (M.L.G.) \\ 2 Department of Agricultural, Forest and Food Science (DISAFA), University of Turin, Largo Paolo Braccini, \\ 2 Grugliasco, Turin 10095, Italy; ambra.prelle@gmail.com \\ 3 Tecnogranda SpA, Via G.B. Conte, 19 Dronero, Cuneo 12025, Italy; dario.vallauri@tecnogranda.it (D.V.); \\ mariachiara.cavallero@tecnogranda.it (M.C.C.) \\ * Correspondence: davide.spadaro@unito.it; Tel.: +39-011-6708942; Fax: +39-011-2368942 \\ + These authors contributed equally to this work.
}

Academic Editor: Shohei Sakuda

Received: 8 March 2016; Accepted: 18 April 2016; Published: 26 April 2016

\begin{abstract}
Aflatoxins, produced by Aspergillus flavus and A. parasiticus, can contaminate different foodstuffs, such as nuts. Cold atmospheric pressure plasma has the potential to be used for mycotoxin detoxification. In this study, the operating parameters of cold atmospheric pressure plasma were optimized to reduce the presence of aflatoxins on dehulled hazelnuts. First, the effect of different gases was tested $\left(\mathrm{N}_{2}, 0.1 \% \mathrm{O}_{2}\right.$ and $\left.1 \% \mathrm{O}_{2}, 21 \% \mathrm{O}_{2}\right)$, then power $(400,700,1000,1150 \mathrm{~W})$ and exposure time $(1,2,4$, and $12 \mathrm{~min})$ were optimized. In preliminary tests on aflatoxin standard solutions, this method allowed to obtain a complete detoxification using a high power for a few minutes. On hazelnuts, in similar conditions $(1000 \mathrm{~W}, 12 \mathrm{~min})$, a reduction in the concentration of total aflatoxins and $\mathrm{AFB}_{1}$ of over $70 \%$ was obtained. Aflatoxins $B_{1}$ and $G_{1}$ were more sensitive to plasma treatments compared to aflatoxins $B_{2}$ and $G_{2}$, respectively. Under plasma treatment, aflatoxin $B_{1}$ was more sensitive compared to aflatoxin $\mathrm{G}_{1}$. At the highest power, and for the longest time, the maximum temperature increment was $28.9^{\circ} \mathrm{C}$. Cold atmospheric plasma has the potential to be a promising method for aflatoxin detoxification on food, because it is effective and it could help to maintain the organoleptic characteristics.
\end{abstract}

Keywords: aflatoxins; cold atmospheric pressure plasma; detoxification; hazelnut; nitrogen; nuts; temperature; time

\section{Introduction}

Italy is the second country, after Turkey, for production of hazelnuts with about 85,000 tons in 2012, representing around 9\% of global supply (914,000 tons) [1]. Hazelnut (Corylus avellana L.) cultivar Tonda Gentile Trilobata is widely cultivated in Piedmont, Northern Italy (15,000 tons in 2014), where it is well adapted to continental climate and it reaches an excellent quality. Confectionery companies process approximately $90 \%$ of Italian hazelnut production, while fresh consumption represents the remaining 10\%. Hazelnuts are consumed both in-shell and shelled. In-shell hazelnuts are generally used as a snack for fresh consumption, while shelled ones are employed as a raw material for food or cosmetic companies [2].

Aflatoxins (AFs) can be found in various foodstuffs, such as nuts, cereals, and spices [3]. Hazelnuts can be contaminated by fungal species belonging to the genus Aspergillus that are able to produce AFs. In particular, $A$. parasiticus is able to produce the four main AFs: $B_{1}\left(\mathrm{AFB}_{1}\right), \mathrm{B}_{2}\left(\mathrm{AFB}_{2}\right)$, 
$\mathrm{G}_{1}\left(\mathrm{AFG}_{1}\right)$, and $\mathrm{G}_{2}\left(\mathrm{AFG}_{2}\right)$, while $A$. flavus is able to produce only $\mathrm{AFB}_{1}$ and $\mathrm{AFB}_{2}$ (Figure 1 ). AFs are highly substituted coumarins, $\mathrm{AFB}_{1}$ and $\mathrm{AFB}_{2}$ have a difuro-coumaro-cyclopentenone structure and emit blue fluorescence, while a six-membered lactone ring replaces the cyclopentenone in $\mathrm{AFG}_{1}$ and $\mathrm{AFG}_{2}$, which emit yellow-green fluorescence [4].<smiles>COc1cc2c(c3oc(=O)c4c(c13)CCC4=O)C1C=COC1O2</smiles><smiles>COc1cc2c(c3oc(=O)c4c(c13)CCOC4=O)C1C=CCC1O2</smiles><smiles>COc1cc2c(c3oc(=O)c4c(c13)CCC4=O)C1CCOC1O2</smiles><smiles>COc1cc2c(c3oc(=O)c4c(c13)CCOC4=O)C1CCCC1O2</smiles>

Figure 1. Structures of the four aflatoxins. $\mathrm{AFB}_{1}(\mathbf{1}) ; \mathrm{AFB}_{2}(2) ; \mathrm{AFG}_{1}(3)$ and $\mathrm{AFG}_{2}(4)$.

$\mathrm{AFB}_{1}$ and $A F G_{1}$ have also an olefinic double bond at the $C_{8}-C_{9}$ position, whereas $A F B_{2}$ and $\mathrm{AFG}_{2}$ lack this bond and are less toxic. The four compounds are closely related and the presence of the furocoumarin configuration places them among a large group of naturally occurring compounds with many toxicological activities. Aflatoxins are genotoxic and carcinogenic and can cause both acute and chronic toxicity in humans [5]. AFs were classified by the International Agency for Research on Cancer (IARC) as carcinogenic agents to humans and animals [6]. The presence of furan ring, lactone ring, and $\mathrm{C}_{8}-\mathrm{C}_{9}$ double bond is associated with mutagenicity, carcinogenicity and teratogenicity of aflatoxin $B_{1}$. The destruction of the $C_{8}-C_{9}$ double bond on the furan ring reduces the toxicity of aflatoxin $\mathrm{B}_{1}$ [7]. $\mathrm{AFB}_{1}$-exo-8,9-epoxide, catalyzed by cytochrome $\mathrm{P} 450$ in mammal liver, is responsible for the carcinogenicity and mutagenicity of $\mathrm{AFB}_{1}$ [8]. The serious health and economic consequences of aflatoxin contamination have created the need for legislative limits, rapid detection techniques, and detoxification strategies [9]. In Europe, maximum levels in foodstuffs for $\mathrm{AFB}_{1}$, aflatoxin $\mathrm{M}_{1}$, and for the sum of aflatoxins $\left(\mathrm{AFB}_{1}, \mathrm{AFB}_{2}, \mathrm{AFG}_{1}\right.$ and $\left.\mathrm{AFG}_{2}\right)$ in nuts are specified by the Commission Regulation (EU) No 165/2010 [10]. Thresholds for AFB 1 and total AFs in hazelnuts for direct human consumption and for use as ingredient in foodstuffs are 5 and $10 \mu \mathrm{g} / \mathrm{kg}$, respectively.

In a batch, nuts contaminated by aflatoxins cannot be visually distinguished from healthy nuts [11]. Aflatoxins tend to accumulate in the external parts of the nuts, particularly in the shell and episperm, where the aflatoxigenic fungi are developing [12]. Detoxification can be very useful in order to recover contaminated commodities. Several detoxification methods, including physical, chemical, or biological tools, were tested against aflatoxins with different degree of success [13].

Plasma, the highly energized fourth state of matter, has been used since the 1990s for bio-decontamination of heat-sensitive materials. The free electrons present in a gas can be accelerated by applying a voltage, to collide with neutral gas atoms causing excitation or ionization. Ionization releases an abundance of highly reactive chemical species, such as positive ions, electrons, excited atoms, UV photons, radicals, and reactive neutral species (reactive oxygen species, ROS, and reactive nitrogen species, RNS) [14]. Depending on the plasma generation system and on the type of gas used, the plasma produced can contain different excited atoms and molecules, ionized gases, radicals, and free electrons [15]. According to the conditions of plasma generation, thermal or non-thermal plasma can be created. The first one is generated at high pressure $\left(\geqslant 10^{5} \mathrm{~Pa}\right)$ and with a minimum power of $50 \mathrm{MW}$. At these conditions the temperatures reached can be very high (from 5 to $20 \times 10^{3} \mathrm{~K}$ ). Non-thermal plasma is obtained at lower pressure and power. Atmospheric pressure techniques, 
besides being cheaper, have the advantage of allowing the formation of a wide range of active species that can react with the macromolecules of contaminants [16]. In the last decade, dielectric barrier discharge (DBD) plasma was applied to inactivate several microorganisms [17,18], including species of Aspergillus and Penicillium $[19,20]$.

This technology is based on an electrical discharge that works at atmospheric pressure. The energy required for the discharge is delivered by a power supply through a quasi-alternative voltage with a frequency in the range $100-150 \mathrm{kHz}$ and a maximum power of $2 \mathrm{~kW}$. The reactive species generated in the discharge depend on the energy applied.

The purpose of this study was to understand the efficacy of low temperature atmospheric pressure plasma treatment on the degradation of AFs in vitro and on hazelnuts. For this study, a prototype of dielectric barrier discharge (DBD) cold atmospheric plasma system was designed. Different gas mixtures ionized to generate the plasma, different powers applied, and different exposure times were tested to evaluate the efficacy of cold atmospheric plasma on detoxification aflatoxins, both in vitro and on raw hazelnuts without shell.

\section{Results and Discussion}

The efficiency of cold atmospheric plasma, generated by ionization of nitrogen and different mixtures of nitrogen/oxygen, was investigated on the reduction of four aflatoxins ( $\mathrm{AFB}_{1}, \mathrm{AFG}_{1}$, $\mathrm{AFB}_{2}$ and $\mathrm{AFG}_{2}$ ). Three exposure times, ranging from 1 to $4 \mathrm{~min}$, were used at the power of $1000 \mathrm{~W}$. Results showed that an increased presence of $\mathrm{O}_{2}$ reduced the efficacy of the cold plasma treatment (Table 1): When oxygen was $21 \%$, the residual $\mathrm{AFB}_{1}$ after plasma treatment was $100 \%$, regardless of exposure time. The efficiency of plasma treatment depended on the nature of gases used to form plasma. The highest detoxification efficacy was obtained with nitrogen or nitrogen/oxygen mixtures $\left(0.1 \% \mathrm{O}_{2}\right)$ for plasma generation and the longest exposure times. The experiments were conducted at atmospheric pressure and in presence of aqueous solutions of the aflatoxins, both factors favoring the production of highly reactive species $\left(\mathrm{OH}, \mathrm{O}^{2-}, \mathrm{H}_{2} \mathrm{O}_{2}, \mathrm{O}_{3}\right)$ that can react with the molecules in the solutions [16]. Different studies reported the efficacy of plasma generated with helium or argon for the inactivation of different species of bacteria or fungal spores [21]. Nitrogen has been widely evaluated for plasma generation, as a substitute of the more expensive noble gases, with several publications reporting the efficacy of this type of plasma treatments [22-24]. Takamatsu et al. [25] investigated the microbial inactivation using non-thermal atmospheric plasma generated with different gases (Ar, $\mathrm{O}_{2}, \mathrm{~N}_{2}, \mathrm{CO}_{2}$, air), and they demonstrated that $\mathrm{CO}_{2}$ and $\mathrm{N}_{2}$ plasmas inactivated Escherichia coli, Pseudomonas aeruginosa, and Staphylococcus aureus better than other tested gases. The presence of oxygen $\left(\mathrm{O}_{2}\right)$ starts the reaction of atomic oxygen with the nitrogen that generates mainly nitrite and nitrate instead of $\mathrm{OH}$ radicals [26].

Table 1. Residual (\%) aflatoxin $B_{1}$ and total aflatoxins on aqueous standard solutions after treatments with atmospheric plasma generated with different gas mixtures and applied for different exposure times (Power $=1000 \mathrm{~W})$.

\begin{tabular}{ccccccc}
\hline Plasma & \multicolumn{3}{c}{$\mathbf{A F B}_{\mathbf{1}} \mathbf{( \% )}$} & \multicolumn{3}{c}{ Afs ${ }^{\mathbf{1}} \mathbf{( \% )}$} \\
\hline gas & $\mathbf{1} \mathbf{~} \mathbf{m i n}$ & $\mathbf{2} \mathbf{~} \mathbf{m i n}$ & $\mathbf{4} \mathbf{~ m i n}$ & $\mathbf{1} \mathbf{~ m i n}$ & $\mathbf{2} \mathbf{~ m i n}$ & $\mathbf{4} \mathbf{~ m i n}$ \\
\hline $21 \% \mathrm{O}_{2}$ & 100 & 100 & 100 & 99.44 & 95.50 & 94.9 \\
$1 \% \mathrm{O}_{2}$ & 100 & $50.2 \pm 17.1$ & $0.50 \pm 0.29$ & 100 & $88.5 \pm 7.55$ & $50.5 \pm 14.0$ \\
$0.1 \% \mathrm{O}_{2}$ & $78.1 \pm 0.07$ & $31.3 \pm 5.98$ & $9.31 \pm 0.27$ & $92.3 \pm 2.89$ & $73.8 \pm 8.49$ & $59.7 \pm 1.49$ \\
$\mathrm{~N}_{2}$ & $87.5 \pm 17.4$ & $20.0 \pm 0.69$ & 0 & $77.9 \pm 11.1$ & $32.8 \pm 4.72$ & $13.7 \pm 0.19$ \\
\hline \multicolumn{3}{r}{ average residual concentration of $\mathrm{AFB}_{1}, \mathrm{AFB}_{2}, \mathrm{AFG}_{1}$, and $\mathrm{AFG}_{2}$, after plasma treatment. }
\end{tabular}

Based on the results about the effect of the gas used on the reduction of aflatoxins, a second set of experiments was designed by using nitrogen for plasma generation. The parameters modified were the power used and the time of exposure to plasma. Experiments on standard solutions showed that the 
four aflatoxins were completely eliminated with treatments at $400 \mathrm{~W}$ for $12 \mathrm{~min}$ (Table 2). An increased treatment effectiveness was observed with increasing the power for plasma generation, from $400 \mathrm{~W}$, to $700 \mathrm{~W}, 1000 \mathrm{~W}$, and $1150 \mathrm{~W}$ (Table 2). A higher power permitted to reduce the treatment times to get a complete aflatoxin removal from aqueous solutions. When the highest power was used, $1 \mathrm{~min}$ was sufficient to reach a total detoxification of the four AFs.

Based on the results in vitro, a similar scheme of plasma treatments were performed on hazelnuts artificially contaminated with aflatoxins. None of the treatments performed on hazelnuts permitted to obtain a total detoxification, but there was a clear trend towards higher detoxification efficacy with increasing either time or power of treatments, similarly as obtained in the in vitro experiments (Table 2). The highest detoxification of $\mathrm{AFB}_{1}(29.1 \pm 5.89)$ and total AFs $(30.4 \pm 9.04)$ was obtained at the highest power $(1150 \mathrm{~W})$ with the longest exposure time (12 min). Previously, Basaran et al. [27] evaluated the efficacy of cold atmospheric air plasma at $300 \mathrm{~W}$ for times ranging from 5 to 20 min against Aspergillus parasiticus and the four aflatoxins, showing an average reduction of $51 \%$ on AFs. In our experiments, cold atmospheric nitrogen plasma and higher powers of treatment permitted to obtain a similar reduction at $400 \mathrm{~W}(54.1 \%$ residual AFs), but a higher efficacy at $1000 \mathrm{~W}(25.8 \%$ residual AFs). The efficiency of non-thermal plasma is associated with the ability to penetrate into the materials and with the quantity of reactive species formed by nitrogen during plasma treatments [28]. Atomic nitrogen and water generate $\mathrm{OH}$ radicals in accordance with the formula: $2 \mathrm{~N}+2 \mathrm{H}_{2} \mathrm{O} \rightarrow \mathrm{N}_{2}$ $+2 \mathrm{OH} \cdot+2 \mathrm{H}$ and they can be responsible for bacterial and fungal inactivation [29]. Dasan et al. [30] investigated the effects of atmospheric pressure plasma decontamination on hazelnuts against $A$. flavus and $A$. parasiticus with scanning electron microscopy. They observed that the integrity of cell structure was completely lost after treatment, by causing cell death and loss of aflatoxins production. The efficacy of the treatment could also depend on the distance between electrodes and target.

Table 2. Residual (\%) aflatoxin $B_{1}$ and total aflatoxins on aqueous standard solutions and on contaminated hazelnuts after treatments with atmospheric plasma generated with different powers and applied for different exposure times.

\begin{tabular}{|c|c|c|c|c|c|}
\hline \multirow{2}{*}{ Power (W) } & \multirow{2}{*}{ Time (min) } & \multicolumn{2}{|c|}{ Standards } & \multicolumn{2}{|c|}{ Hazelnuts ${ }^{1}$} \\
\hline & & $\mathrm{AFB}_{1}(\%)$ & $\mathrm{AFs}^{2}(\%)$ & $\mathrm{AFB}_{1}(\%)$ & $\mathrm{AFs}^{2}(\%)$ \\
\hline \multirow{4}{*}{400} & 1 & $25.4 \pm 6.13$ & $57.1 \pm 28.8$ & $100 \pm 1.60$ & $97.7 \pm 13.6$ \\
\hline & 2 & $7.75 \pm 0.17$ & $20.6 \pm 14.6$ & $100 \pm 5.10$ & $98.7 \pm 23.9$ \\
\hline & 4 & $4.49 \pm 0.80$ & $9.40 \pm 6.41$ & $83.2 \pm 27.5$ & $81.2 \pm 30.0$ \\
\hline & 12 & 0 & 0 & $54.3 \pm 0.91$ & $54.1 \pm 6.01$ \\
\hline \multirow{4}{*}{700} & 1 & $12.7 \pm 6.08$ & $44.3 \pm 25.6$ & $99.6 \pm 68.6$ & $90.9 \pm 41.6$ \\
\hline & 2 & 0 & $6.61 \pm 1.94$ & $84.7 \pm 15.2$ & $84.7 \pm 10.2$ \\
\hline & 4 & 0 & 2.40 & $83.1 \pm 6.81$ & $83.9 \pm 30.2$ \\
\hline & 12 & 0 & 0 & $44.8 \pm 3.36$ & $52.9 \pm 10.7$ \\
\hline \multirow{4}{*}{1000} & 1 & $9.52 \pm 4.70$ & $24.0 \pm 12.1$ & $96.2 \pm 6.50$ & $88.5 \pm 12.9$ \\
\hline & 2 & 0 & 0.60 & $82.5 \pm 30.2$ & $79.9 \pm 34.8$ \\
\hline & 4 & 0 & 0 & $78.5 \pm 10.7$ & $66.9 \pm 11.8$ \\
\hline & 12 & 0 & 0 & $35.7 \pm 0.87$ & $25.8 \pm 13.2$ \\
\hline \multirow{4}{*}{1150} & 1 & 0 & 0 & $85.2 \pm 8.46$ & $81.7 \pm 20.3$ \\
\hline & 2 & 0 & 0 & $60.2 \pm 3.31$ & $62.0 \pm 13.4$ \\
\hline & 4 & - & - & $50.6 \pm 9.77$ & $60.0 \pm 20.8$ \\
\hline & 12 & - & - & $29.1 \pm 5.89$ & $30.4 \pm 9.04$ \\
\hline
\end{tabular}

${ }^{1}$ Mean Initial concentrations of AFB1, and AFs where $8.02 \mathrm{ng} / \mathrm{g}$ and $36.11 \mathrm{ng} / \mathrm{g}$ respectively; ${ }^{2}$ Average residual concentration of $\mathrm{AFB}_{1}, \mathrm{AFB}_{2}, \mathrm{AFG}_{1}$, and $\mathrm{AFG}_{2}$, after plasma treatment.

Aflatoxins $B_{1}$ and $G_{1}$ were more sensitive to plasma treatments compared to aflatoxins $B_{2}$ and $G_{2}$, respectively (Figure 2). In addition, Basaran et al. [27], using cold atmospheric air plasma on hazelnuts, showed that $\mathrm{AFG}_{2}$ was the least sensitive mycotoxin. This is in accordance with the mechanism 
described by McKenzie et al. [31] that suggests a direct ozone attack to the double bonds of $\mathrm{AFB}_{1}$ and $A F G_{1}$, while $A F B_{2}$ and $A F G_{2}$ are less reactive to ROS because of the lack of $C_{8}-C_{9}$ double bond. This is a very positive feature, because $A F B_{1}$ and $A F G_{1}$ are the most toxic aflatoxins. The process of degradation of aflatoxins using ozonation has been widely studied [32]. The opening of terminal furan ring is promoted by the reaction of ozone with the $\mathrm{C}_{8}-\mathrm{C}_{9}$ double bond that is the most reactive site. $\mathrm{OH}$ radicals, that are strong oxidizing agents, increase the ability of ozone to react with the olefinic site of $\mathrm{AFB}_{1}$ [33].

Degradation of $\mathrm{AFB}_{1}$ has been widely studied [34,35]. The detoxification of $\mathrm{AFB}_{1}$ initially involves the formation of a $\beta$-keto acid structure due to the opening of the lactone ring followed by the formation of aflatoxin $\mathrm{D}_{1}$ or aflatoxin $\mathrm{D}_{2}$ [36]. Additionally, $\mathrm{AFG}_{1}$ degradation has been investigated by Velazhahan et al. [37], who suggest the modification of lactone ring structure with the formation of two different metabolites. Cytochrome P450 catalyzes the formation of the epoxide group, considered the carcinogenic and mutagenic form of $\mathrm{AFB}_{1}$. After the opening of lactone ring and the loss of the $\mathrm{C}_{8}-\mathrm{C}_{9}$ double bond, the formation of $\mathrm{AFB}_{1}-$ exo-8,9-epoxide is blocked [38]. As reported by McKenzie et al. [31], ozonolysis induce $\mathrm{AFB}_{1}$ degradation and the breakdown products are non-toxic or lower toxic compounds, due to complete degradation of toxins or partly chemical modification. The identity and toxicity of breakdown products of aflatoxins after plasma treatment were not determined in this work.

Under plasma treatment, $\mathrm{AFB}_{1}$ was more reactive compared to aflatoxin $\mathrm{G}_{1}$, in accordance with Baertschi et al. [39] that investigated the reactivity of $\mathrm{AFB}_{1}, \mathrm{AFG}_{1}$ and sterigmatocystin in presence of epoxides. Computation studies clearly demonstrated that an electron deficiency on the carbonylic carbon on lactone ring favored the nucleophilic attack that induced the hydrolysis of this site [37].

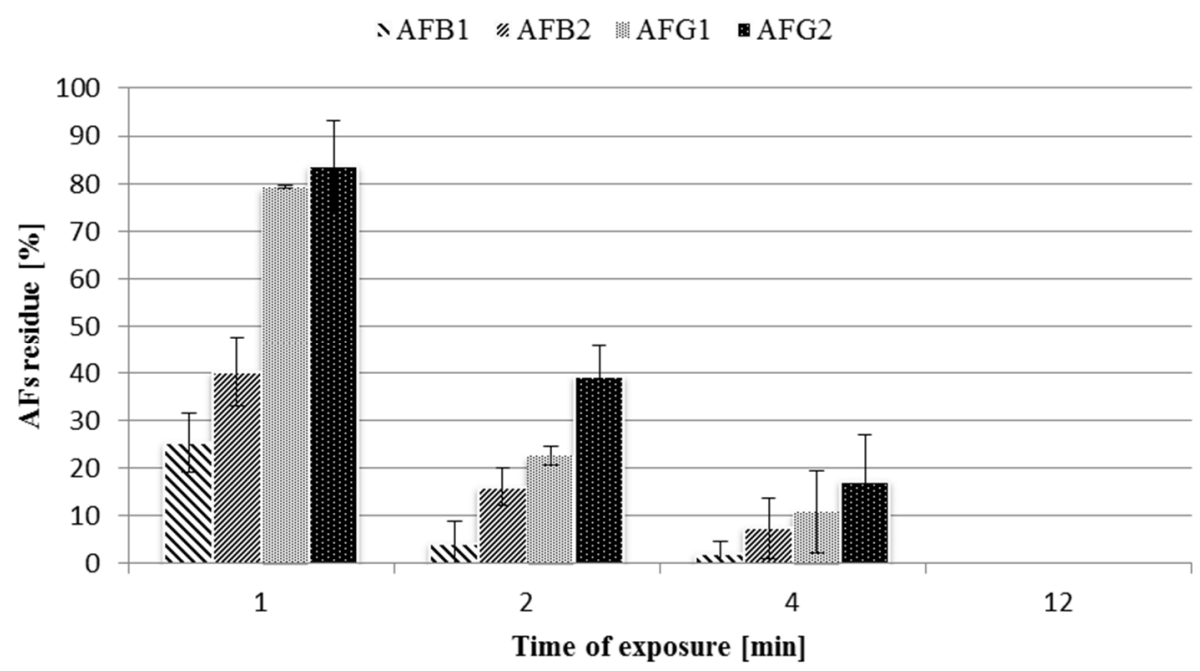

Figure 2. Residue of $\mathrm{AFB}_{1}, \mathrm{AFB}_{2}, \mathrm{AFG}_{1}$ and $\mathrm{AFG}_{2}$ after a treatment at $400 \mathrm{~W}$ on standard solutions.

Temperature in the treatment zone was monitored throughout the experiments at the beginning and at the end of treatment. In Figure 3, the increase in temperature during plasma treatments at different powers are reported.

Higher powers led to an increase of $\Delta \mathrm{T}$, with the maximum increment, equal to $28.9{ }^{\circ} \mathrm{C}$ $\left(\mathrm{T}_{\max }=58.9^{\circ} \mathrm{C}\right)$, reached using the longest time exposure at the maximum power. These $\Delta \mathrm{T}$ are not expected to affect the qualitative properties of hazelnuts, making the plasma treatment compatible with the food processing. On the contrary, the use of atmospheric microwave-induced argon plasma to degrade three mycotoxins $\left(\mathrm{AFB}_{1}\right.$, nivalenol and deoxynivalenol) resulted in temperature increases over $100{ }^{\circ} \mathrm{C}[13]$. In the choice of the treatment, we should consider that microwave-induced argon plasma is quicker, because the treatment lasts a few seconds, while cold atmospheric plasma is effective after a few minutes of treatment, but this latter one could help to maintain the organoleptic characteristics. 


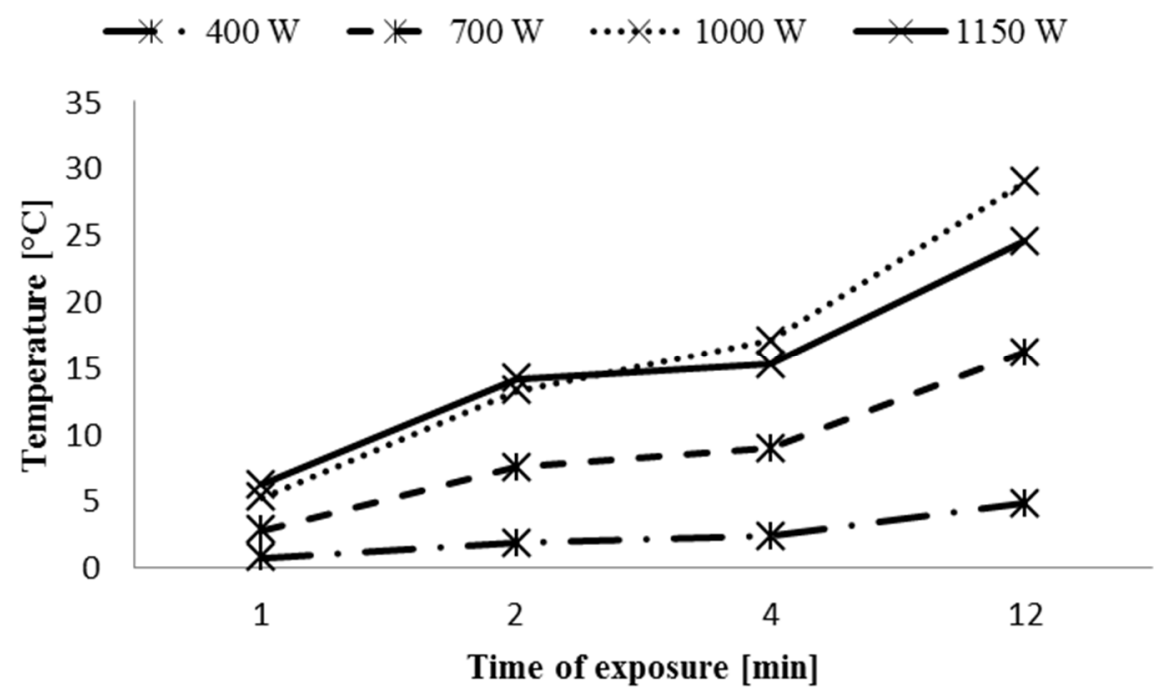

Figure 3. Increase in temperature $\left(\Delta \mathrm{T}^{\circ} \mathrm{C}\right)$ during treatments.

\section{Conclusions}

Cold atmospheric pressure plasma is quite well established in various industrial processes, and its use is also potentially promising in the food sector, in particular for microbial and mycotoxin inactivation $[29,30]$. The possibility to modify the operating conditions, such as power, gas composition, and time of treatment, permits to adapt this technology to naturally contaminated food matrices. In the scaling up of the prototype, the system could be included in the hazelnut processing chain, after dehulling and before roasting. Compared to microwave-induced argon plasma, this treatment lasts longer, but it looks more promising because it does not increase significantly the temperature of the food matrix. Further, naturally contaminated hazelnuts and the different parts of nuts, such as shell, episperm, and kernel will be analyzed. By considering the effect of the treatment on aflatoxins, the amount and toxicity of the breakdown products will be determined. Future works will also evaluate the physical-chemical properties, the structural changes, and the organoleptic properties of the food matrix after treatment.

\section{Materials and Methods}

\subsection{Materials}

$\mathrm{AFB}_{1}$ (purity $\geqslant 98 \%$ ), $\mathrm{AFB}_{2}$ (purity $\geqslant 98 \%$ ), $\mathrm{AFG}_{1}$ (purity $\geqslant 98 \%$ ) and $\mathrm{AFG}_{2}$ (purity $\geqslant 98 \%$ ) standards were purchased from Sigma-Aldrich (St. Louis, MO, USA) and dissolved in methanol in order to prepare a working solution of $10 \mathrm{mg} / \mathrm{mL}$. LC-MS grade methanol, acetonitrile acetic acid, and water, used as mobile phases and as extraction solvents, were purchased from Sigma-Aldrich. $\mathrm{NaCl}, \mathrm{KCl}, \mathrm{Na}_{2} \mathrm{HPO}_{4}$, and $\mathrm{KH}_{2} \mathrm{PO}_{4}$ used to prepare phosphate-buffered saline (PBS) solution were purchased from Merck (Darmstadt, Germany) and dissolved in ultrapure water (Maina, Turin, Italy). AflaTest WB immunoaffinity columns were purchased from Vicam (Watertown, MA, USA).

\subsection{Atmospheric Pressure Plasma System}

A dielectric barrier discharge (DBD) cold atmospheric plasma system produced by AcXys Technologies (St. Martin Le Vinoux, France) was used (Figure 4). The system was modified to include an isolated chamber in order to maintain the sample under controlled atmosphere and temperature. The plasma technology is developed around an electrical discharge that works at an operative pressure of about 7 bar. The central electrode is covered with a dielectric coating to prevent any cathode spot that could derive in arcs. The gap between the electrodes is $1 \mathrm{~mm}$. The outer electrode is made out of aluminum steel. Gas mixture flows through the structure crosswise. It travels in and out 
through two slots longitudinally opposed. Flow velocity and gas mixture can be controlled according to the process requirement. The DBD plasma system can work with pure $\mathrm{N}_{2}$ gas or mixtures with a prevalence of $\mathrm{N}_{2}$, including air. The standard operative gas flow was about $120 \mathrm{~L} / \mathrm{min}$. The energy fed to the discharge was delivered by a power supply through a quasi-alternative voltage with a frequency in the range 100-150 kHz and a power in the range between 0.4 and $2 \mathrm{~kW}$. Cooling was added to keep the system under safe mode of operation. The parameters that could be controlled are electrical power, time of exposure, gas composition, and distance of the treated samples from the plasma source. In all the experiments, the distance was fixed at about $50 \mathrm{~mm}$.

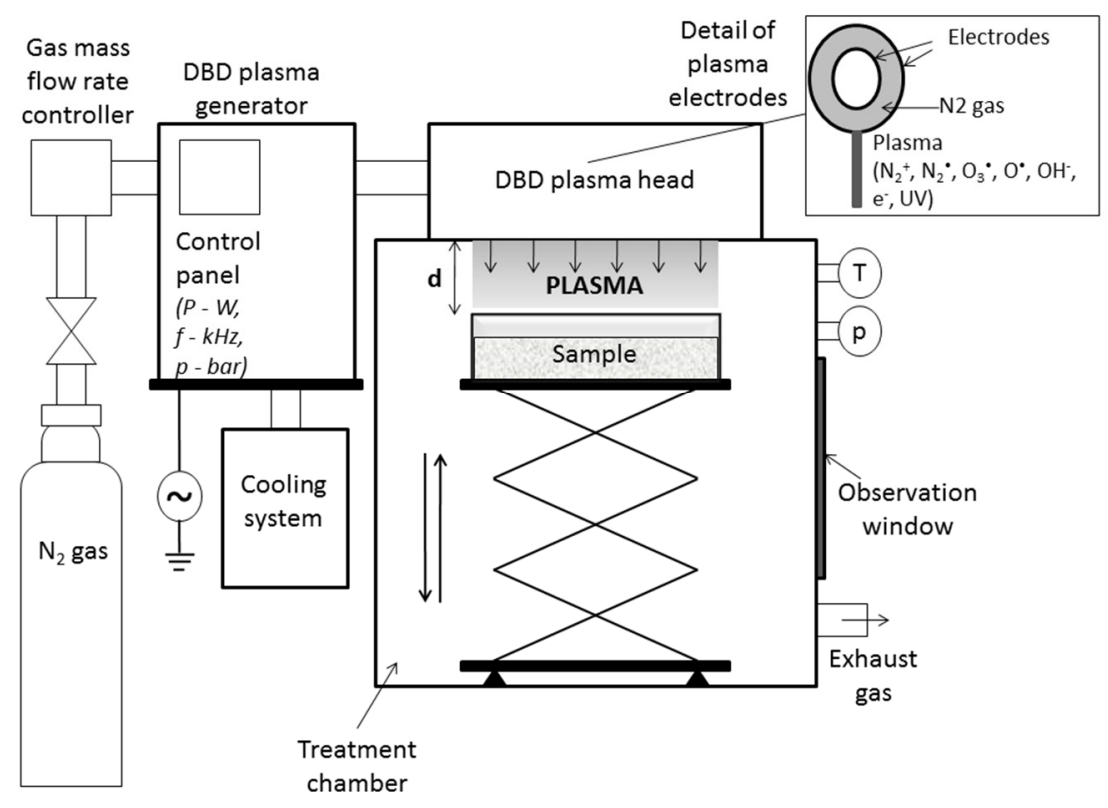

Figure 4. Schematic diagram of the plasma system used in this work for treatments.

\subsection{Efficacy of Gas Mixtures on Aflatoxin Detoxification}

A mixture of AFs standards were prepared by diluting original standards at the final concentration of $10 \mathrm{ng} / \mathrm{mL}$ in Petri dishes containing $10 \mathrm{~mL}$ of water. Pure $\mathrm{N}_{2}$, and three mixtures of nitrogen/oxygen $\left(21 \%, 1 \%\right.$, and $0.1 \%$ of $\left.\mathrm{O}_{2}\right)$ were used for plasma generation. The samples were treated with a power of $1000 \mathrm{~W}$ for three exposure times (1,2, and $4 \mathrm{~min})$. Each treatment was performed on three sample replicates. The experiments were performed twice.

\subsection{Effect of Power and Exposure Time on Aflatoxin Detoxification in Vitro}

For the second experimental set up, pure $\mathrm{N}_{2}$ was chosen for plasma generation. The mixture of AFs standards were prepared as previously described. The samples were treated with four powers $(400 \mathrm{~W}, 700 \mathrm{~W}, 1000 \mathrm{~W}, 1150 \mathrm{~W})$ applied for four exposure times (1, 2, 4, and $12 \mathrm{~min})$. Each treatment was performed on three sample replicates. The experiments were performed twice.

\subsection{Effect of Power and Exposure Time on Aflatoxin Detoxification in Hazelnut}

Raw hazelnuts free from aflatoxins were harvested in Cortemilia $\left(44^{\circ} 34^{\prime} 44^{\prime \prime} 04 \mathrm{~N}, 08^{\circ} 11^{\prime} 38^{\prime \prime} 40 \mathrm{E}\right)$, Northern Italy, and provided by La Gentile s.r.l. Raw hazelnuts without shell were artificially contaminated at the final concentration on hazelnuts of $20 \mathrm{ng} / \mathrm{g}$ each aflatoxin by spraying a solution of the four AFs. For each treatment, $40 \mathrm{~g}$ of contaminated hazelnuts were used. The samples were treated with four powers $(400 \mathrm{~W}, 700 \mathrm{~W}, 1000 \mathrm{~W}, 1150 \mathrm{~W})$ applied for four exposure times (1, 2, 4, and $12 \mathrm{~min})$. Each treatment was performed on three sample replicates. The experiments were performed twice. 
Throughout the experiments, the temperature of the chamber was monitored through a temperature probe placed at about $2 \mathrm{~cm}$ from the plasma source.

\subsection{Extraction, Clean-up and LC-MS/MS Conditions}

The extraction method described by Prelle et al. [40] was used. Twenty-five grams of grounded hazelnuts were extracted with $5 \mathrm{~g}$ of $\mathrm{NaCl}$ and $125 \mathrm{~mL}$ of a $\mathrm{H}_{2} \mathrm{O}: \mathrm{CH}_{3} \mathrm{OH}(20: 80 v / v)$ solution for $2 \mathrm{~h}$ on a rotary shaker. The extract was filtered through Whatman No.4 filter paper to eliminate solid particles and then filtered by using a Whatman PDVF $0.45 \mu \mathrm{m}$ syringe filter (Whatman $\mathrm{GmbH}$, Dussel, Germany). An aliquot of $10 \mathrm{~mL}$ of filtrate was diluted 1:1 in ultrapure water and used for purification procedure using immunoaffinity columns. After conditioning, diluted samples were loaded and flushed under a flow of $0.5 \mathrm{~mL} / \mathrm{min}$. Columns were washed with PBS solution and water. AFs were eluted with $3 \mathrm{~mL}$ of methanol and the eluate was evaporated to dryness. One $\mathrm{mL}$ $\mathrm{H}_{2} \mathrm{O}: \mathrm{CH}_{3} \mathrm{OH}(90: 10 \mathrm{v} / \mathrm{v})$ acidified with $0.1 \%$ acetic acid was added to the residue and vortexed before HPLC-MS/MS analysis.

Analysis was performed using a previously validated method [40] using Varian Model 212-LC micro pumps (Palo Alto, CA, USA) with a Varian autosampler Model 410 Prostar coupled with a Varian 310-MS triple quadrupole mass spectrometer with an electrospray ion source operating in positive ionization mode. For chromatographic separation, a Pursuit XRs Ultra C18 $(100 \mathrm{~mm} \times 2.0 \mathrm{~mm}, 2.8 \mu \mathrm{m}$, Varian, Cernusco sul Naviglio (MI), Italy) analytical column was used. Column temperature was set at $30{ }^{\circ} \mathrm{C}$, eluents were $\mathrm{H}_{2} \mathrm{O}(\mathrm{A})$ and $\mathrm{CH}_{3} \mathrm{OH}(\mathrm{B})$, both acidified with $0.1 \% \mathrm{CH}_{3} \mathrm{COOH}$, flow was set at $0.2 \mathrm{~mL} / \mathrm{min}$. The gradient was set as follows: $0-25 \mathrm{~min}$ from $90 \%$ to $15 \%$ of $\mathrm{A} ; 25-28 \mathrm{~min}$ from $15 \%$ to $90 \%$ of $\mathrm{A} ; 28-30 \mathrm{~min} 90 \%$ of $\mathrm{A}$. Monitoring reaction mode (MRM) transitions used for quantification were: $313>285$ (CE $14 \mathrm{~V}$ ) for $\mathrm{AFB}_{1}, 315>287$ (CE $18 \mathrm{~V}$ ) for $\mathrm{AFB}_{2}, 329>243$ (CE $\left.18 \mathrm{~V}\right)$ for $\mathrm{AFG}_{1}$, $331>245$ (CE $24 \mathrm{~V}$ ) for $\mathrm{AFG}_{2}$. The collision gas (Ar) pressure was set at 2 mbar for all experiments.

AFs quantification was performed using external calibration based on serial dilution of a multi-analyte stock solution. Results were corrected by recoveries that had been determined by spiking five different blank samples at three concentration levels.

Acknowledgments: Work carried out with a grant from the Piedmont Region, under the project "ITACA-Technological Innovation, Automation and new Analytical Controls to improve the quality and safety of the Piedmontese food products". We thank Fabio Canova (La Gentile s.r.l.) for providing the hazelnuts for experimentation.

Author Contributions: D.S., A.P., and D.V. conceived and designed the experiments; A.P., I.S., and M.C.C. performed the experiments; I.S., A.P., and D.S. analyzed the data; M.L.G. contributed reagents, materials and equipment; I.S., D.S., D.V., and M.C.C. wrote the paper; M.L.G. and A.G. critically revised the manuscript.

Conflicts of Interest: The authors declare no conflict of interest.

\section{References}

1. FAOSTAT. Crops. Production. Available online: http://faostat.fao.org/site/567/DesktopDefault.aspx? PageID=567\#ancor (accessed on 2 December 2015).

2. USDA Foreign Agricultural Service. Tree Nuts Annual 2014; GAIN Report Number IT1483; USDA: Washington, DC, USA, 2015.

3. Prelle, A.; Spadaro, D.; Garibaldi, A.; Gullino, M.L. Co-occurrence of aflatoxins and ochratoxin A in spices commercialized in Italy. Food Control. 2014, 39, 192-197. [CrossRef]

4. Wogan, G.N. Chemical nature and biological effects of the aflatoxins. Bacteriol. Rev. 1966, 30, 460-470. [PubMed]

5. Williams, J.H.; Phillips, T.D.; Jolly, P.E.; Stiles, J.K.; Jolly, C.M.; Aggarwal, D. Human aflatoxicosis in developing countries: A review of toxicology, exposure, potential health consequences, and interventions. Am. J. Clin. Nutr. 2004, 80, 1106-1122. [PubMed]

6. IARC. Monograph on the evaluation of carcinogenic risk to humans. In Some Traditional Herbal Medicines, Some Mycotoxins, Naphthalene and Styrene; IARC: Lyon, France, 2002; Volume 82. 
7. Wogan, G.N.; Edwards, G.S.; Newberne, P.N. Structure activity relationships in toxicity and carcinogenicity of aflatoxins and analogs. Cancer Res. 1971, 31, 1936-1941. [PubMed]

8. Guengerich, F.P.; Shimada, T. Activation of procarcinogens by human cytochrome P450 enzymes. Mutat. Res. Fundam. Mol. Mech. Mutagen. 1998, 400, 201-213. [CrossRef]

9. Ricciardi, A.; Castagna, R.; Ferrante, I.; Frascella, F.; Marasso, S.L.; Ricci, A.; Canavese, G.; Lorè, A.; Prelle, A.; Gullino, M.L.; et al. Development of a microcantilever-based immunosensing method for mycotoxin detection. Biosens. Bioelectron. 2013, 40, 233-239. [CrossRef] [PubMed]

10. Commission Regulation (EU) No 165/2010 of 26 February 2010 Amending Regulation (EC) No 1881/2006 Setting Maximum Levels for Certain Contaminants in Foodstuffs as Regards Aflatoxins; European Union: Bruxelles, Belgium, 2010; pp. 8-12.

11. Statement of the Scientific Panel on Contaminants in the Food Chain on a request from the European Commission on the effects on public health of an increase of the levels for aflatoxin total from $4 \mu \mathrm{g} / \mathrm{kg}$ to $10 \mu \mathrm{g} / \mathrm{kg}$ for tree nuts other than almonds, hazelnuts and pistachios. EFSA J. 2009, 1168, 1-11.

12. Baltaci, C.; İlyasoğlu, H.; Cavrar, S. Aflatoxin levels in raw and processed hazelnuts in Turkey. Food Addit. Contam. B 2012, 5, 83-86. [CrossRef] [PubMed]

13. Park, B.J.; Takatori, K.; Sugita-Konishi, Y.; Kim, I.H.; Lee, M.H.; Han, D.W.; Chung, K.H.; Hyun, S.O.; Park, J.C. Degradation of mycotoxins using microwave-induced argon plasma at atmospheric pressure. Surf. Coat. Technol. 2007, 201, 5733-5737. [CrossRef]

14. Niemira, B.A. Cold plasma reduction of Salmonella and Escherichia coli O157:H7 on almonds using ambient pressure gases. J. Food Sci. 2012, 77, M171-M175. [CrossRef] [PubMed]

15. Moisan, M.; Barbeau, J.; Moreau, S.; Pelletier, J.; Tabrizian, M.; Yahia, L. Low-temperature sterilization using gas plasmas: A review of the experiments and an analysis of the inactivation mechanisms. Int. J. Pharm. 2001, 226, 1-21. [CrossRef]

16. Moreau, M.; Orange, N.; Feuilloley, M.G.J. Non-thermal plasma technologies: New tools for bio-decontamination. Biotechnol. Adv. 2008, 26, 610-617. [CrossRef] [PubMed]

17. Boudam, M.K.; Moisan, M.; Saoudi, B.; Popovici, C.; Gherardi, N.; Massines, F. Bacterial spore inactivation by atmospheric-pressure plasmas in the presence or absence of UV photons as obtained with the same gas mixture. J. Phys. D Appl. Phys. 2006, 39, 3494-3507. [CrossRef]

18. Fridman, G.; Brooks, A.D.; Balasubramanian, M.; Fridman, A.; Gutsol, A.; Vasilets, V.N.; Ayan, H.; Friedman, G. Comparison of direct and indirect effects of non-thermal atmospheric-pressure plasma on bacteria. Plasma Process. Polym. 2007, 4, 370-375. [CrossRef]

19. Selcuk, M.; Oksuz, L.; Basaran, P. Decontamination of grains and legumes infected with Aspergillus spp. and Penicillium spp. by cold plasma treatment. Bioresour. Technol. 2008, 99, 5104-5109. [CrossRef] [PubMed]

20. Suhem, K.; Matan, N.; Nisoa, M.; Matan, N. Inhibition of Aspergillus flavus on agar media and brown rice cereal bars using cold atmospheric plasma treatment. Int. J. Food Microbiol. 2013, 161, 107-111. [CrossRef] [PubMed]

21. Laroussi, M. Sterilization of contaminated matter with an atmospheric pressure plasma. IEEE Trans. Plasma Sci. 1996, 24, 128-135. [CrossRef]

22. Van Bokhorst-van de Veen, H.; Xie, H.; Esveld, E.; Abee, T.; Mastwijk, H.; Nierop Groot, M. Inactivation of chemical and heat-resistant spores of Bacillus and Geobacillus by nitrogen cold atmospheric plasma evokes distinct changes in morphology and integrity of spores. Food Microbiol. 2015, 45, 26-33. [CrossRef] [PubMed]

23. Fernández, A.; Noriega, E.; Thompson, A. Inactivation of Salmonella enterica serovar Typhimurium on fresh produce by cold atmospheric gas plasma technology. Food Microbiol. 2013, 33, 24-29. [CrossRef] [PubMed]

24. Mols, M.; Mastwijk, H.; Nierop Groot, M.; Abee, T. Physiological and transcriptional response of Bacillus cereus treated with low-temperature nitrogen gas plasma. J. Appl. Microbiol. 2013, 115, 689-702. [CrossRef] [PubMed]

25. Takamatsu, T.; Uehara, K.; Sasaki, Y.; Hidekazu, M.; Matsumura, Y.; Iwasawa, A.; Ito, N.; Kohno, M.; Azuma, T.; Okino, A. Microbial inactivation in the liquid phase induced by multigas plasma jet. PLoS ONE 2015, 10, e0132381.

26. Takamatsu, T.; Kawate, A.; Uehara, K.; Oshita, T.; Miyahara, H.; Dobrynin, D. Bacterial inactivation in liquids using multi-gas plasma. Plasma Med. 2012, 2, 237-247. [CrossRef]

27. Basaran, P.; Basaran-Akgul, N.; Oksuz, L. Elimination of Aspergillus parasiticus fron nut surface with low pressure cold plasma (LPCP) treatment. Food Microbiol. 2008, 25, 626-632. [CrossRef] [PubMed] 
28. Akishev, Y.; Grushin, M.; Karalnik, V.; Trushkin, N.; Kholodenko, V.; Chugunov, V.; Kobzev, E.; Zhirkova, N.; Irkhina, I.; Kireev, G. Atmospheric-pressure, nonthermal plasma sterilization of microorganisms in liquids and on surfaces. Pure Appl. Chem. 2008, 80, 1953-1969. [CrossRef]

29. Surowsky, B.; Schlüter, O.; Knorr, D. Interactions of non-thermal atmospheric pressure plasma with solid and liquid food systems: A review. Food Eng. Rev. 2015, 7, 82-108. [CrossRef]

30. Dasan, B.G.; Mutlu, M.; Boyaci, I.H. Decontamination of Aspergillus flavus and Aspergillus parasiticus spores on hazelnut via atmospheric pressure fluidized bed plasma reactor. Int. J. Food Microbiol. 2016, 216, 50-59. [CrossRef] [PubMed]

31. McKenzie, K.S.; Kubena, L.F.; Denvir, A.J.; Rogers, T.D.; Hitchens, G.D.; Bailey, R.H.; Harvey, R.B.; Buckley, S.A.; Phillips, T.D. Aflatoxicosis in turkey poults is prevented by treatment of naturally contaminated corn with ozone generated by electrolysis. Poult. Sci. 1998, 77, 1094-1102. [CrossRef] [PubMed]

32. Proctor, A.D.; Ahmedna, M.; Kumar, J.V.; Goktepe, I. Degradation of aflatoxins in peanut kernels / flour by gaseous ozonation and mild heat treatment. Food Addit. Contam. 2004, 21, 786-793. [CrossRef] [PubMed]

33. Diao, E.; Hou, H.; Dong, H. Ozonolysis mechanism and influencing factors of aflatoxin B1: A review. Trends Food Sci. Technol. 2013, 33, 21-26. [CrossRef]

34. Lee, L.S.; Stanley, J.B.; Cucullu, A.F.; Pons, W.A.; Goldblatt, L.A. Ammoniation of aflatoxin B1: Isolation and identification of the major reaction product. J. AOAC 1974, 57, 626-631.

35. Cucullu, A.F.; Lee, L.S.; Pons, W.A.; Stanley, J.B. Ammoniation of aflatoxin B1: Isolation and characterization of a product with molecular weight 206. J. Agric. Food Chem. 1976, 24, 408-410. [CrossRef] [PubMed]

36. Mendez-Albores, A.; Nicolas-Vazquez, I.; Miranda-Ruvalcaba, R.; Moreno-Martinez, E. Mass spectrometry/mass spectrometry study on the degradation of B-aflatoxins in maize with aqueous citric acid. Am. J. Agric. Biol. Sci. 2008, 3, 482-489.

37. Velazhahan, R.; Vijayanandraj, S.; Vijayasamundeeswari, A.; Paranidharan, V.; Samiyappan, R.; Iwamoto, T.; Friebe, B.; Muthukrishnan, S. Detoxification of aflatoxins by seed extracts of the medicinal plant, Trachyspermum ammi (L.) Sprague ex Turrill—Structural analysis and biological toxicity of degradation product of aflatoxin G1. Food Control. 2010, 21, 719-725. [CrossRef]

38. Diaz, G.J.; Murcia, H.W. Biotransformation of Aflatoxin B1 and Its Relationship with the Differential Toxicological Response to Aflatoxin in Commercial Poultry Species. In Aflatoxins-Biochemistry and Molecular Biology, 1st ed.; Guevara-González, R.G., Ed.; InTech: Rijeka, Croatia, 2011; pp. 3-20.

39. Baertschi, S.W.; Raney, K.D.; Shimada, T.; Harris, T.M.; Guengerich, F.P. Comparison of rates of enzymatic oxidation of aflatoxin B1, aflatoxin G1, and sterigmatocystin and activities of the epoxides in forming guanyl-N7 adducts and inducing different genetic responses. Chem. Res. Toxicol. 1989, 2, 114-122. [CrossRef] [PubMed]

40. Prelle, A.; Spadaro, D.; Garibaldi, A.; Gullino, M.L. Aflatoxin monitoring in Italian hazelnut products by LC-MS. Food Addit. Contam. B 2012, 5, 279-285. [CrossRef] [PubMed]

(C) 2016 by the authors; licensee MDPI, Basel, Switzerland. This article is an open access article distributed under the terms and conditions of the Creative Commons Attribution (CC-BY) license (http://creativecommons.org/licenses/by/4.0/). 